\title{
Intervention with the Lidcombe Program for a Bilingual School-Age Child Who Stutters in Iran
}

\author{
Mehdi Bakhtiar ${ }^{a, b} \quad$ Ann Packman ${ }^{c}$ \\ aSpeech Therapy Department, School of Paramedicine, and ${ }^{b}$ Research Center for the Health of Children and \\ Adolescents, Zahedan University of Medical Sciences, Zahedan, Iran; ${ }^{\mathrm{C}}$ Australian Stuttering Research Centre, \\ The University of Sydney, Sydney, N.S.W., Australia
}

\section{Key Words}

Stuttering $\cdot$ Lidcombe Program • Bilingual $\cdot$ School age • Iran

\begin{abstract}
Objective: In this study, the immediate and extended effects of the Lidcombe Program were investigated for the first time in Iran. Treatment in the Lidcombe Program is carried out by the child's parent (or carer) in the child's everyday environment. The program has been shown to be effective with preschool children who stutter (i.e. younger than 6 years) and to a lesser extent with older children. Participant and Method: The participant was a bilingual (Baluchi-Persian) boy aged 8 years 11 months. Treatment was conducted in both languages. Stuttering severity was measured in Baluchi with the parental rating scale, and in Persian with percentage of syllables stuttered (\%SS). Results: The child completed stage 1 of the program in 13 weeks. \%SS was less than 1 during the last 3 clinic visits and severity ratings made by the parent indicated no stuttering (severity rating $=1$ ) for all days of the final week. Speech recordings made beyond the clinic in both languages also indicated stuttering at below $1 \%$ SS. The child met all criteria for stage 2 in both languages, over 10 months. Conclusion: This case report suggests that the Lidcombe Program could be suitable for bilingual Iranian children who stutter.

Copyright $\odot 2009$ S. Karger AG, Basel
\end{abstract}

\section{Introduction}

Stuttering typically starts in the third and fourth years of life [1]. While around $74-80 \%$ of the children recover naturally [2], without effective treatment the remaining children will go on stuttering into adolescence and adulthood. There are a number of treatments for early stuttering [3], which take a variety of approaches both direct and indirect. However, the Lidcombe Program [4] is the only treatment that has been subjected to randomized controlled trials [5-7].

\section{The Lidcombe Program}

The Lidcombe Program is a behavioral treatment, which is based on operant principles. The parent gives verbal contingencies (comments) for stutter-free speech and for stuttering during prescribed periods each day. The speech-language pathologist (SLP) teaches the parent how to do this during weekly visits to the clinic. Treatment effects are measured by the parents during everyday life with a 10-point severity rating scale (SR), and by the clinician who measures stuttering frequency (percent of syllables stuttered, \%SS) at each clinic visit.

During stage 1 of the program, the parent provides treatment for prescribed periods each day, first in structured conversations and later in normal everyday conversations. The parent and the child attend the clinic once a

\section{KARGER}

Fax +4161306 1234 E-Mail karger@karger.ch www.karger.com
Prof. Ann Packman

Australian Stuttering Research Centre

University of Sydney

PO Box 170, Lidcombe, N.S.W. 1825 (Australia)

Tel. +61 29351 9061, Fax +61 29351 9392, E-Mail a.packman@usyd.edu.au 
week. The goal of stage 2 is to maintain the treatment benefits of stage 1 . The median number of clinic visits taken to meet the criteria for entry to stage 2 (\%SS less than 1 and SRs 2 or 1 with the majority being 1 ) has been shown to be 11, although this number varies according to stuttering severity [8]. However, since the study by Kingston et al. [8] the treatment manual has been updated to state that children must meet these criteria for 3 consecutive clinic visits; hence the median number of clinic visits needed to proceed to stage 2 is now estimated to be around 14. The current Lidcombe Program manual can be downloaded from the website of the Australian Stuttering Research Centre: www.fhs.usyd.edu.au/asrc. The Lidcombe Program has shown the most success with preschool children (up to age 6 years) $[5,9,10]$. The program is also used with older children, although it appears to be less effective with children aged 6 years and older [11].

The Lidcombe Program is now used in many countries around the world, for example in Canada [12], the UK [13], New Zealand [14], South Africa [15], Germany [6], Holland [16] and the USA [17]. One reason for its popularity is that the parents can do the treatment according to their own parenting style and cultural traditions. This means it is easy to apply the principles of the treatment through languages other than English, which is the language in which it was developed.

\section{Bilingual Children and the Lidcombe Program}

There is ongoing discussion in the literature about whether speaking more than 1 language in preschool years increases a child's risk of starting to stutter [see 1820]. However, to date there is no clear evidence that this is the case.

The Lidcombe Program is particularly valuable for working with bilingual children who stutter because it can be applied in the preferred language, or indeed in both languages, even if the SLP does not speak the language in which it is applied [18]. This circumvents, to a considerable extent, some of the problems highlighted in a recent survey of the management of bilingual children with communication disorders [21].

There have been a number of case reports of the Lidcombe Program being used with bilingual children (for an overview see [18]). These have been for children who speak English and French, English and Arabic, or English and Portuguese. In a group comparison, Shenker [22] found no difference between 39 monolingual and 17 bilingual Canadian children in the time taken to complete stage 1 of the program.

The Lidcombe Program in Iran

\section{The Present Study}

The current report is about the use of the Lidcombe Program with an 8 years and 11 months old bilingual boy who stutters, in Iran. Clinical services for communication disorders are widely available in Iran [23]. However, many SLPs avoid giving direct treatment to preschool children who stutter, with family counseling and minimizing communicative pressures on the child being the common approaches. Although the boy was no longer in the preschool age range, it was decided to use the Lidcombe Program as he had not had any previous treatment for his stuttering and he had a supportive family. There is also a report of the program being used with an English/Arabic-speaking child aged 6 years [18]. This is the first time the Lidcombe Program has been used in Iran. In preparation for introducing the program to Iran, the first author and colleagues translated the text by Onslow et al. [4] into Persian. In addition, a Persian translation of the program manual is available on the website of the Australian Stuttering Research Centre, www.fhs.usyd. edu.au/asrc.

Iran is a linguistically and culturally diverse country. Persian (Farsi) is the dominant language and most Iranians speak and understand Persian well. The other languages spoken include Luri, Gilaki, Mazandarani, Azeri (Turkic), Kurdish, Balochi (Baluchi), Arabic, Armenian and Assyrian. Thus, many people in Iran speak more than 1 language. Baluchi and Persian belong to the family of Indo-Iranian languages. They have different syntactical structures especially in word order and there are also some differences between the speech sounds. While the vocabulary is different, a number of Persian words are used when Baluchi is spoken. Arabic script is typically used for speakers of both languages and there is no formal education in Baluchi writing.

In this study, we investigated the immediate and extended effect of the Lidcombe Program in a school-age child in Iran, for both languages (Baluchi and Persian). The study was approved by the local ethics committee and informed consent was obtained from the father. The name used in this report has been changed for ethical reasons.

\section{Method}

\section{Participant}

Meysam was 8 years and 11 months of age when brought to the speech clinic for the first time by his father. His stuttering comprised repeated syllables and fixed postures of the speech organs, consisting of vowel prolongations and some audible blocks. He was referred by his teacher as his stuttering had recently been get- 
Fig. 1. Daily stuttering SRs, measured by parents, and weekly stuttering frequency, measured by the clinician, for Meysam, over 13 weeks.

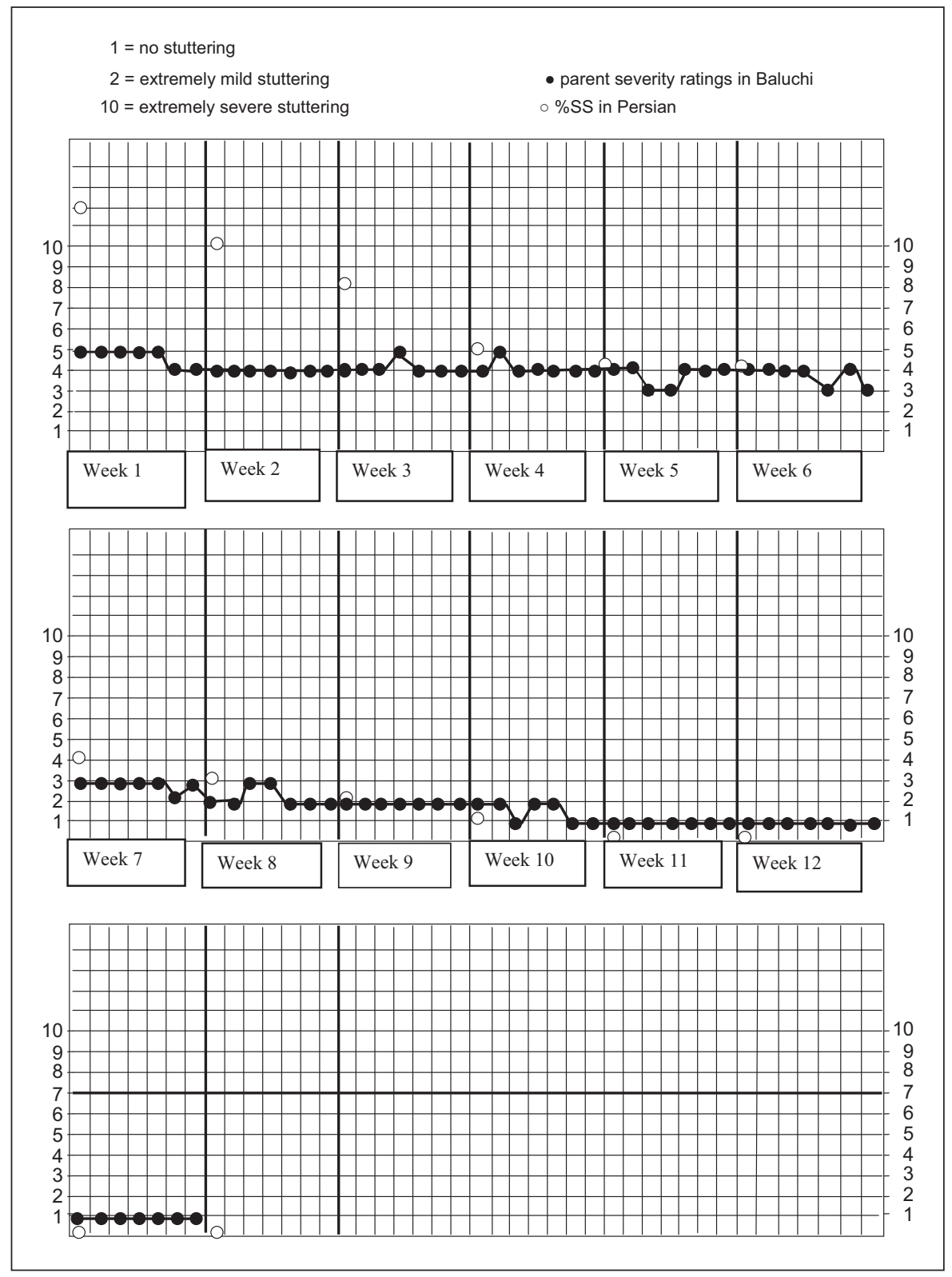

ting worse. He came from a family of 9: 5 children, 2 parents and 2 uncles. They were living in the city of Zahedan, which is the capital of the Sistan and Baluchestan province in eastern Iran. Meysam's parents could not remember the exact time of onset of his stuttering but were certain it began before the age of 6 years. The parents believed that he would recover spontaneously but his present teacher advised them that he should receive therapy immediately.

Baluchi was Meysam's first language and he spoke it with his family, relatives and peers, and during daily activities (shopping, religious activity and so forth). He spoke Persian at school and with a few friends, and used it for his school reading and writing assignments. In his neighborhood the age of first exposure to Per- sian as a second language is typically around 5 years. However, Meysam did not really use Persian until he started school at 7 years. Despite this, his mastery of speaking and comprehending Persian was excellent and his father reported that he was doing very well at school and was achieving excellent grades in all subjects. He had no health issues or any other speech and/or language or hearing problems. The parents reported that nobody in their immediate or extended family had stuttered or had any other speech or language problems.

\section{Treatment and Results}

At the first clinic visit Meysam was assessed by 2 SLPs who specialized in stuttering. The stuttering frequency was measured 
at $12 \%$ SS by both SLPs during a conversation conducted in Persian between Meysam, his father and the treating SLP (the first author). In the Lidcombe Program the stuttering frequency is measured in real time, typically with a dual-button counter timer. As the child talks, the observer pushes 1 button for every syllable judged to be unambiguously stuttered and the other button for every other syllable spoken.

The Lidcombe Program was suggested along with other options for therapy, and the father agreed to do it. The SLP demonstrated the child's stuttering behaviors and what the Lidcombe Program would involve. The SLP and the father agreed to use 'error' as the verbal contingency for stuttering and to acknowledge and praise stutter-free speech with contingencies such as 'correct', 'right' or 'nice speaking' in Persian and Baluchi. The words used as contingencies were identical in each language. The child accepted all the terms and did not respond negatively to them. It was agreed that the father would do structured treatment in Persian and unstructured treatment in Baluchi, and that the SLP would demonstrate treatment in Persian in the clinic. The SLP then showed the father how to rate the child's speech using the Lidcombe Program 10-point severity scale and instructed him to note down the severity of Meysam's stuttering during everyday conversations, for each day of the week. These SRs were always for Baluchi.

The program was administered throughout according to the treatment manual. At each clinic visit the parent brought the daily measured SRs (for Baluchi) to the clinic and \%SS was measured by the treating SLP in the clinic during a conversation in Persian. The daily SR and the weekly \%SS measures are shown in figure 1. Each week the parent demonstrated the treatment in Persian for the SLP, and the required changes were discussed.

At the fifth clinic visit the SLP recommended to do unstructured treatment in Baluchi during everyday life. On the next clinic visit the father reported that other family members besides himself, including Meysam's uncles (who were trained directly by the clinician), mother and older siblings were now all participating actively in the treatment process and presenting verbal contingencies at home. He reported that Meysam enjoyed their attention to his speech and was spontaneously attempting to correct errors in his speech. The SLP instructed the parent to give special praise for spontaneous self-corrections. Subsequently, the father shook his hand whenever Meysam spontaneously corrected his errors, and Meysam seemed to find this reinforcement enjoyable. The clinician suggested to Meysam that he correct his stutters spontaneously during speech at home whenever he recognized them, and the child agreed.

Meysam did not attend the clinic for 2 sessions due to holidays but the parent reported the results to the SLP and recorded his speech samples during everyday speaking.

The clinician asked Meysam's father to provide audio recording in both languages at home. So at the next clinic visit the clinician and the parent measured both of the out-clinic speech samples, and the results were less than $1 \%$ SS for each. Although the clinician's first language was Persian, he could track the stuttering in Baluchi. The clinician also requested Meysam's teacher to assign SRs for all the days of week 13 when he was speaking Persian at school. These were 1 for 5 days and 2 for 2 days of the week. The recorded in- and out-clinic speech samples in both languages were also scored as at or near $0 \%$ SS.

The Lidcombe Program in Iran
Samples of Meysam speaking in Persian were recorded at the last 3 clinic visits and were measured for \%SS by the SLP and remeasured by an independent rater. The samples were of 10, 4 and 3 min duration, and all were longer than 300 syllables. These independent \%SS scores were also all below $1 \%$ SS. A recording was also made outside the clinic and \%SS was measured by 2 SLPs independent of the study. Both observers rated \%SS as less than 1 . Therefore, the child completed stage 1 after 13 weeks (12 clinic visits).

Meysam entered stage 2 of the program, and the speech criteria were met at each stage 2 clinic visit over a 10 -month period. The parent SRs were mainly $1 \mathrm{~s}$ with occasional $2 \mathrm{~s}$. At each visit, Baluchi conversational speech samples were recorded and replayed, and Meysam's father and the clinician together confirmed the absence of stuttering.

\section{Discussion}

In this clinical report the treatment effects of the Lidcombe Program were measured in a school-age bilingual Iranian child. This is the first documented use of the Lidcombe Program in Iran. As mentioned by some investigators of the Lidcombe Program [20], the effectiveness of this program may not differ substantially among children from non-English-speaking background. The present study confirmed this. The child took 13 weeks and 12 clinic visits to complete stage 1 of the program, which is around the median time taken in a file audit of Australian and English preschool children [8]. Moreover, the results were sustained to the end of stage 2 , which lasted 10 months. The child had been stuttering for more than 2 years, and at his age it is very unlikely that the reductions in stuttering were due to natural recovery. While there are conflicting reports about the effectiveness of the Lidcombe Program with children over 6 years, the present report indicates that it is possible to complete this program successfully with an 8-year-old child in the same time as previously reported with preschool children.

There are a number of factors that may have contributed to the success of the treatment. First, it was delivered in both languages; that is, nonstructured treatment in the child's first language (Baluchi) and structured treatment in the child's second language (Persian). Second, the treatment was administered by more than 1 family member. It is possible that this may be beneficial when the program is administered to older children, such as Meysam. Further research would be needed to determine the extent to which these 2 factors influence progress in the Lidcombe Program.

Third, the program was accepted readily by both Meysam and his family. As stated earlier, one of the 
strengths of the Lidcombe Program is that it can be delivered according to parenting style and cultural values. The present results with Meysam suggest that the program is likely to be accepted readily by Iranian families.

\section{Acknowledgment}

The authors thank the child and his family for participating in this study.

\section{References}

1 Guitar B: Stuttering. An Integrated Approach to Its Nature and Treatment. Philadelphia, Lippincott, Williams \& Wilkins, 2006.

2 Yairi E, Ambrose N: Early Stuttering for Clinicians by Clinicians. Austin, Pro Ed, 2005.

3 Onslow M, Packman A (eds): Handbook of Early Stuttering Intervention. San Diego, Singular Publishing Group, 1999.

4 Onslow M, Packman A, Harrison E (eds): The Lidcombe Program of the Early Stuttering Intervention. A Clinician's Guide. Austin, Pro-Ed, 2003.

5 Jones M, Onslow M, Packman A, Williams S, Ormond T, Schwartz I, Gebski V: A randomised controlled trial of the Lidcombe Program of early stuttering intervention. $\mathrm{Br}$ Med J 2005;331:659-661.

6 Lattermann C, Euler HA, Neumann K: A randomized control trial to investigate the impact of the Lidcombe Program on early stuttering in German-speaking preschoolers. J Fluency Disord 2008;33:52-65.

7 Lewis C, Packman A, Onslow M, Simpson J: A Phase II trial of telehealth delivery of the Lidcombe Program of Early Stuttering Intervention. Am J Speech Lang Pathol 2008;17: 139-149.

8 Kingston M, Huber A, Onslow M, Jones M, Packman A: Predicting treatment time with the Lidcombe Program: replication and meta-analysis. Int J Lang Commun Disord 2003;38:165-177.
-9 Harris V, Onslow M, Packman A, Harrison E, Menzies R: An experimental investigation of the impact of the Lidcombe Program on early stuttering. J Fluency Dis 2002;27:203214.

10 Rousseau I, Packman A, Onslow M, Harrison E, Jones M: An investigation of language and phonological development and responsiveness of preschool age children to the Lidcombe Program. J Commun Disord 2006;40: 382-397.

11 Lincoln M, Onslow M, Lewis C, Wilson L: A clinical trial of an operant treatment for school-age children who stutter. Am J Speech Lang Pathol 1996;5:73-85.

12 Shenker R, Wilding J: The Lidcombe Program around the world; Canada; in Onslow M, Packman A, Harrison E (eds): The Lidcombe Program of Early Stuttering Intervention. A Clinician's Guide. Austin, ProEd, 2003, pp 161-171.

13 Hayhow R, Kingston, M, Ledzion R: The Lidcombe Program around the world; The United Kingdom; in Onslow M, Packman A, Harrison E (eds): The Lidcombe Program of Early Stuttering Intervention. A Clinician's Guide. Austin, Pro-Ed, 2003, pp 147-158.

14 Jones M, Blakeley M, Ormond T: The Lidcombe Program around the world; New Zealand; in Onslow M, Packman A, Harrison E (eds): The Lidcombe Program of Early Stuttering Intervention. A Clinician's Guide. Austin, Pro-Ed, 2003, pp 173-181.

15 Wahlhaus MM, Girson J, Levy C: The Lidcombe Program around the world; South Africa; in Onslow M, Packman A, Harrison E (eds): The Lidcombe Program of Early Stuttering Intervention. A Clinician's Guide. Austin, Pro-Ed, 2003, pp 183-190.
16 Franken M-C, Kielstra-Van der Schalk CJ, Boelens H: Experimental treatment of early stuttering: a preliminary study. J Fluency Disord 2005;30:189-199.

17 Miller B, Guitar B: Long-term outcome of the Lidcombe Program for Early Stuttering. American Journal of Speech-Language Pathology 2009; 18:42-49.

18 Roberts PM, Shenker RC: Assessment and treatment of stuttering in bilingual speakers; in Curlee RF, Conture EG (eds): Stuttering and Related Disorders of Fluency, ed 3. New York, Thieme Medical Publishers, 2007, pp 183-209.

19 Howell P, Davis SR, Williams R: The effects of bilingualism on stuttering during late childhood. Arch Dis Child 2009;94:42-46.

20 Packman A, Onslow M, Reilly S, Attanasio J, Shenker R: Stuttering and bi-lingualism. Arch Dis Child 2009;94:248.

21 Jordan H: Clinical intervention for bilingual children. An international survey. Folia Phoniatr Logop 2008;60:97-105.

22 Shenker RC: Bilingualism in early stuttering: empirical issues and clinical implications; in Bothe A (ed): Evidence-Based Treatment of Stuttering. Empirical Bases and Clinical Applications. Mahwah, Erlbaum \& Associates, 2004, pp 81-96.

23 Nilipour R: Emerging issues in speech therapy in Iran. Folia Phoniatri Logopaed 2002; 54:65-68. 